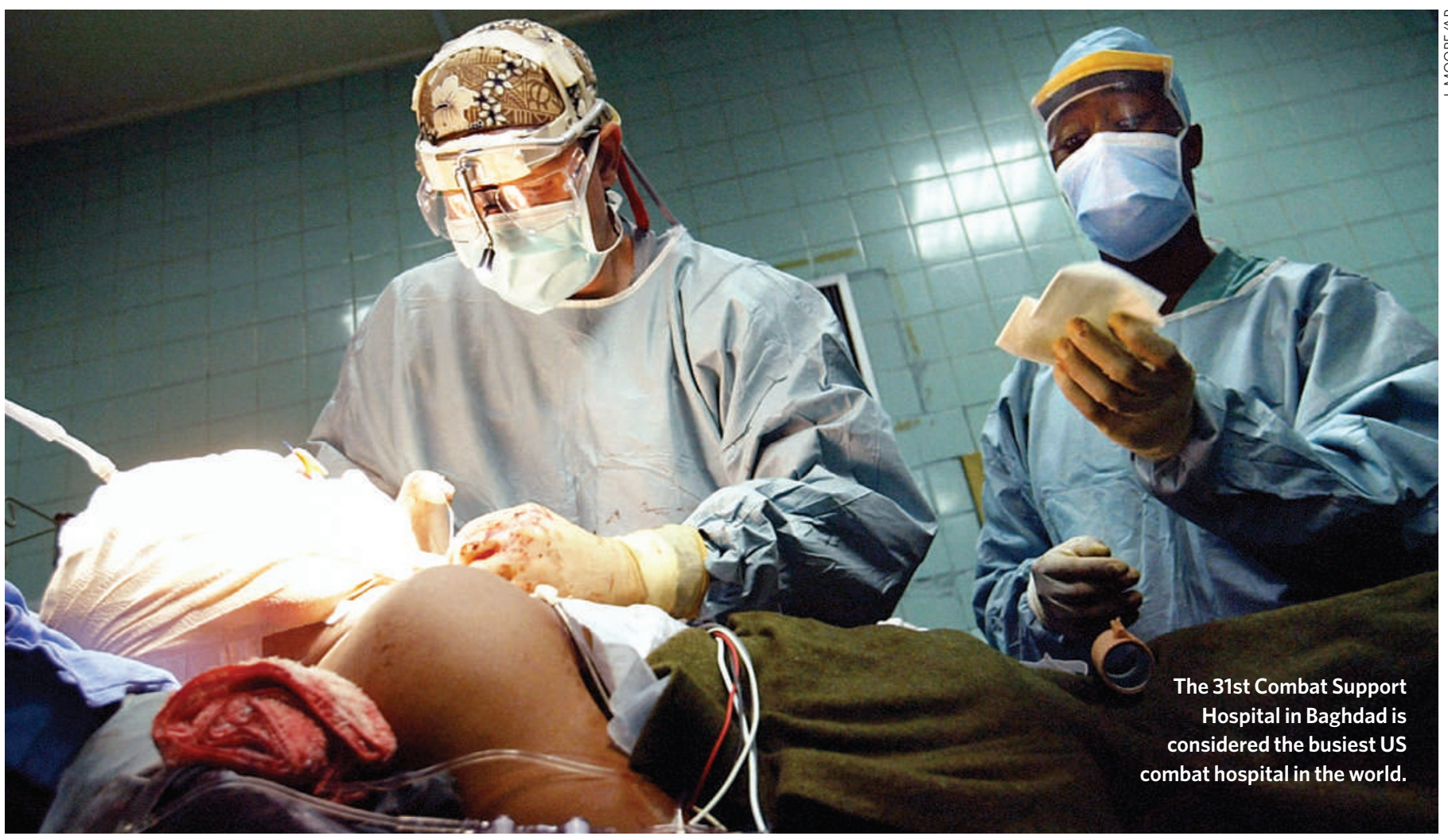

\title{
The war against wounds
}

The US military is getting a lot of flak for the way it treats wounded soldiers returning from Iraq. Emma Marris reports on the advances in medical care that are helping to bring them home.

1 any numbers can be used to tell the stories of war. Almost 3,500 Americans dead in Iraq and Afghanistan. Some 24,000 injured servicemen and women. Other numbers are subject to their own skirmishes: estimates of the number of civilian Iraqi dead are hotly contested and range from tens of thousands to half a million. Every number tells a story.

A little-known number is that since 2001, the wars in Iraq and Afghanistan have had a US military case fatality rate - the percentage of injured soldiers who die - of 9.4. That is, of 100 people wounded, 9.4 of them will die, either instantly or later, from their wounds. This compares with case fatality rates of 15.8 in Vietnam and 19.1 in the Second World War ${ }^{1}$. The reasons for the decline in the current conflicts are better armour, logistics and medical tools.

Battlefield medicine has often led to advances in trauma care. Florence Nightingale's sanitary reforms in hospitals during the Crimean War are a classic example. In the 1950s Korean War, improved resuscitation of the wounded and rapid air evacuation to Mobile Army Surgical Hospitals - the famous MASH units - reduced the US hospital mortality rate by 24\% compared with the Second World War ${ }^{2}$.

John Holcomb, commander of the US Army Institute of Surgical Research in Fort Sam
Huston, Texas, summarizes the advances in the current conflicts as "training, protection and devices". The devices that he and other trauma surgeons point to are better body armour, redesigned tourniquets and advanced clotting aids and transfusion fluids. But all the military personnel interviewed for this story stressed the importance of training and preparation: most surgeons sent to Iraq and Afghanistan are first required to spend time in a civilian trauma centre.

Teasing apart the actual contributions of individual advances to the lower body count is a much greater challenge. Many data are classified or unavailable. Perhaps the most scientific of all the wartime advances in Iraq is the creation of the Joint Theater Trauma Registry. For the first time, solid data are being collected for trauma cases from injury through to recovery. "We are able to get a sense about what kind of improvements can be made in the body armour," explains Paul Cordts, who runs the office that sets policy at the office of the US Army Surgeon General. "We can see what kind of body armour the casualty was wearing, what damage there was to the vehicles, and what happened to the casualties."

This data collection and analysis is intended to guide future improvements in medical training and equipment, but also to investigate the effect of procedural changes made during the current conflicts. "For all these wars - and we have had a lot of wars - we have never done any thorough data collection," says Basil Pruitt, editor of the Journal of Trauma. "Now they can really identify the outcomes of these patients and figure out what is particularly beneficial."

For Pruitt, the steady improvement in survival continues a historical trend: "The survival from serious wounds has increased as the time between injury and arrival at a definitive hospital has decreased. That started in the First World War really." The Korean war took this further by making rapid helicopter transfers to surgical units routine practice. Now, he says, such units are better equipped: "They have a whole panoply of specialists. If you have a head injury, you do better now than you used to do because you have neurosurgeons."

Military medicine often begins just seconds after a wounding, because all soldiers and marines now carry one-handed tourniquets and clotting agents with them to help slow down blood loss. The main agents used are QuikClot, which comes as a sponge or as 
powder, and HemCon, which is in bandage form. No one knows exactly how many lives they save: "Getting data from the fog of war isn't easy," says Raymond Huey, chief executive of Z-Medica in Wallingford, Connecticut, the company that makes QuikClot.

\section{Far-forward thinking}

QuikClot powder is made of porous minerals called zeolites. The story is that inventor Frank Hursey, who was working with zeolites as sieves to separate gases, cut himself shaving and applied it to his face on a whim. How it works is still unclear, although it has been approved for clinical use. "There is a whole lot of surface chemistry," says Huey. The product also includes calcium ions, catalysts for the body's clotting process. It is carried by every marine and by members of a number of other forces.

HemCon bandages rely on chitin molecules, which are obtained from shrimp shells. The chitin is extremely sticky and glues the bandage to the flesh "like super duct tape", according to Mike Zoormajian, product manager at HemCon Medical Technologies in Portland, Oregon. Then, the positively charged chitin attracts and clumps together the negatively charged blood cells. Zoormajian says that the product was developed after casualties in Somalia bled to death in the streets because no medics could reach them. Since 2005, every US soldier serving in the Middle East carries at least one of these bandages. Zoormajian thinks that the bandages have saved well over 100 lives.

Once a medic gets to a wounded soldier, the solider enters a rapid and organized system.

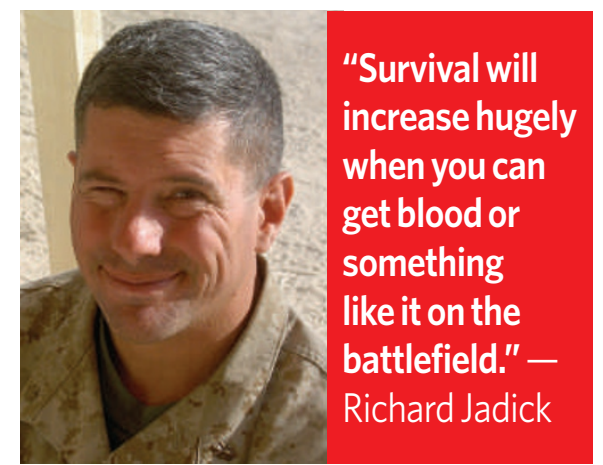

The casualty is stabilized far-forward - that is, right up in amongst the action - and then sent to a nearby aid station, where they are patched up further and sent to a Combat Support Hospital. From there, they might be flown to Landstuhl Regional Medical Center in Germany or on to Walter Reed Army Medical Center in Washington DC. All this often happens inside a week. Speed really does save people with battlefield injuries. The alternative can be bleeding to death.

\section{Saving lives}

For Richard Jadick, a surgeon deep in the heart of Falluja, Baghdad, with the 8th Marine regiment in 2004, it was Hespan - a colloid solution - that saved lives. During a sustained battle, Jadick put the far-forward concept to its extreme, setting up an aid station in an abandoned prayer room, with stretchers up on cement blocks and bullets ricocheting outside. Colloids such as Hespan contain starch molecules that pull water into the veins from other tissues. "Hespan was a huge player," says Jadick. "It keeps fluid in the vein. But you are going to see a huge increase in combat survival when you can get blood or something like it on the battlefield."

Surgeons such as Jadick know that the most severely injured casualties - about $10 \%$ are not only losing blood but fighting shock, hypothermia and, unhelpfully, lowered blood clotting. The answer is to get the blood volume back up - but with how much of what fluid on what timeline? Jadick had only Hespan to hand, but medics at units farther back from the action have access to various blood fractions and crystalloids - solutions of water and electrolytes - in addition to colloids.

\section{Pressure points}

Civilian doctors generally use crystalloids and colloids initially and transfuse blood or plasma later. But as of 3 January, military policy has been to give the patients something close to real blood as quickly as possible. This might mean warm blood donated by a fellow soldier or an infusion of thawed red blood cells and plasma (in a one-to-one ratio). According to Holcomb, Hespan and other products get the blood pressure back up, but do nothing to restore clotting. The clotting factors in human blood or blood products are what is needed. And because keeping blood on ice is tricky on the battlefield, other technologies will be needed.

Cellphire - a company based in Rockville, Maryland - is freeze-drying platelets, which help with clotting, to lengthen their storage time. At room temperature, platelets keep for

\section{After the battle}

Five or six men with high and tight military haircuts are working out in the physical therapy room of Walter Reed Army Medical Center in Washington DC. They are manipulating large balls, hopping, working the Stairmaster - and they've got maybe three legs between them. Today they are being inundated with visitors as Walter Reed tries to solicit better publicity after its outpatient care became the target of media and political outrage.

But even though their housing unit is mouldy and harbours vermin, and the hospital is leaving Washington DC in 2011, work is continuing on a new amputee ward. Iraqi veteran amputees have received so much attention from the US media that it comes as a surprise to learn that as of February, there were only 562 of them. Still, advances in prosthetics keep coming, including prosthetic arms that operate from signals sent from the nerves that once controlled the missing limb, and have been transplanted to the upper chest.

The most common wounds are those caused by explosive devices. Estimates suggest that more than 5,000 of the US wounded could have brain injuries, some of whom will benefit from a new tool called 'rapid prototyping'. This technique is used by engineers to make quick three-dimensional prototypes from computer models. At Walter Reed, the inputs are computed tomography (CT) scans of injured heads and hips. Instructions are sent to a machine that builds a model by laying down thousands of $0.125-\mathrm{mm}$ layers of plastic.

Several floors below the physical therapy room, Stephen Rouse

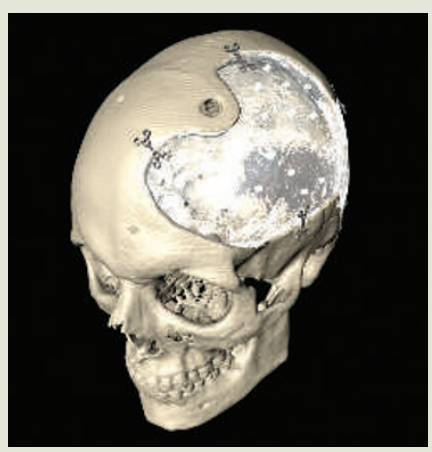

Models are used to guide surgery. offers visitors candy out of a model of his own cranium before explaining how the prototypes can help. If surgeons know exactly what to expect before they open up a patient, they can reduce operation times and improve outcomes. Models are also used to construct customized implants. Rouse hopes soon to buy a machine that will make titanium implants directly from a CT scan, so they will be a perfect fit.

Rouse says Walter Reed has performed several hundred craniectomies on soldiers, all of whom would have died in previous conflicts. He also stresses the positive psychological effects a skull implant has on these patients, who suffer from personality 
only a few days, but the freeze-dried products can be rehydrated with sterile solution when the need arises. Cellphire hopes to have their product in clinical tests in 18 months.

\section{Joint effort}

Holcomb stresses that no advance can save lives on its own. Speed won't help, if you don't have the right devices. All the blood in the world is no good if your body armour has let you down. The goal of military medicine is moving the right people to the right places at the right time - what Holcomb calls "the trauma systems approach".

The Joint Theater Trauma Registry should reveal how well all the parts of this system work. Body protection, for example, has improved enormously since the flak jackets of Vietnam. Materials science has created ever-better protective gear - such as lighter Kevlar vests that are more resistant to bullets and shrapnel. Ceramic inserts and add-ons are available for the upper arms, neck, groin and other areas. As a result, wounds now tend to be to the arms, legs and head, with far fewer chest injuries.

The amount that body armour has contributed to the lower case fatality rate in Iraq and Afghanistan is unknown, as are many other figures that might reveal the truth behind the lower case fatality rate. Despite the lack of data, Holcomb and others argue that battlefield medicine has consistently produced medical advances, some of which transfer to civilian practice.

Although US civilians might have wars to thank for helicopter pads on hospitals and pro-

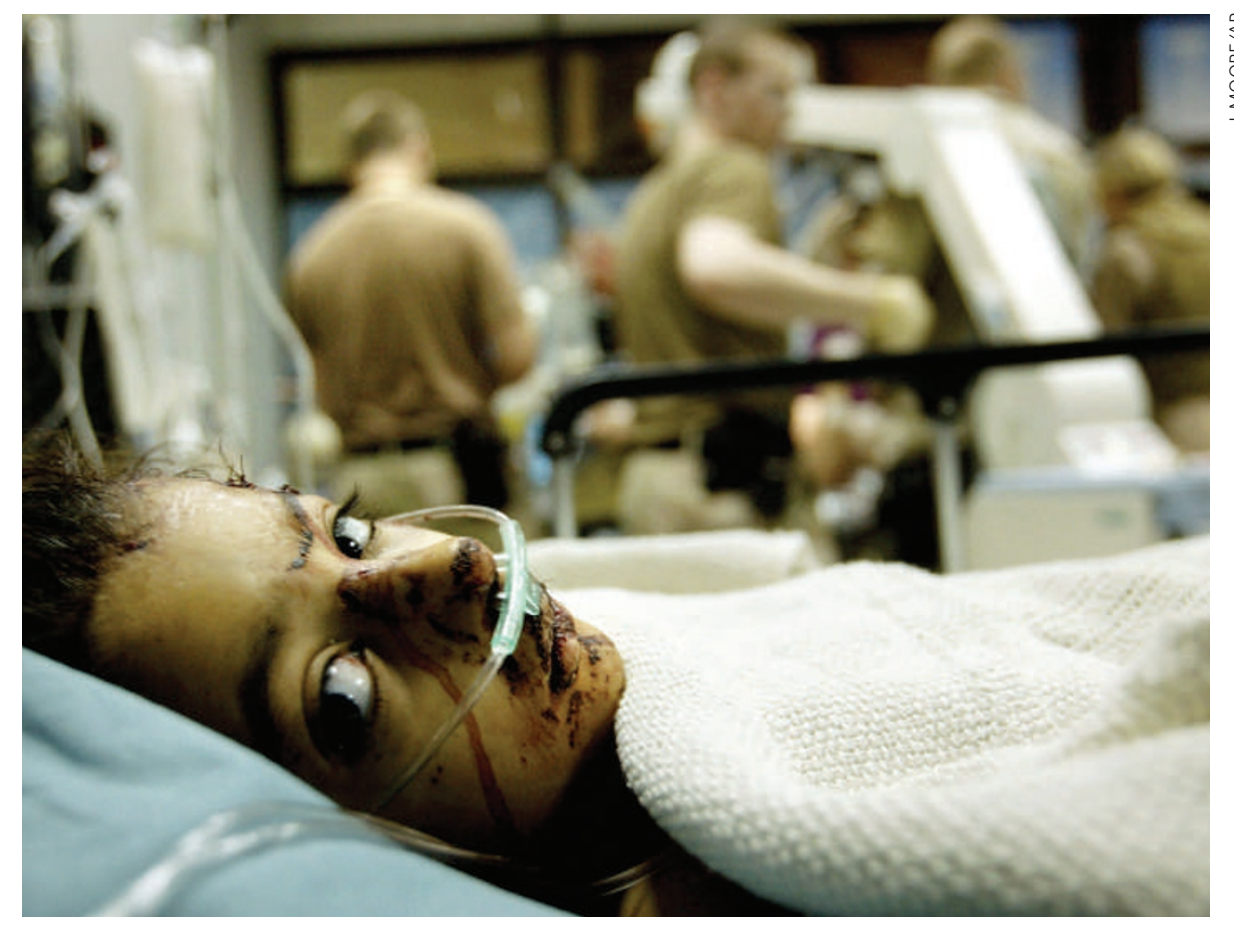

Combat support hospitals occasionally provide care for Iraqi civilians.

cedures for massive trauma, Iraqi citizens are getting the trauma without the advances. US care for wounded Iraqis is often no more than a goodwill gesture. General healthcare is bad. Worse, the poor security situation is leading Iraqi doctors to flee the country: up to $30 \%$ of qualified physicians are estimated to have left since 2003. Many doctors are targeted for threats and attacks by unknown parties and

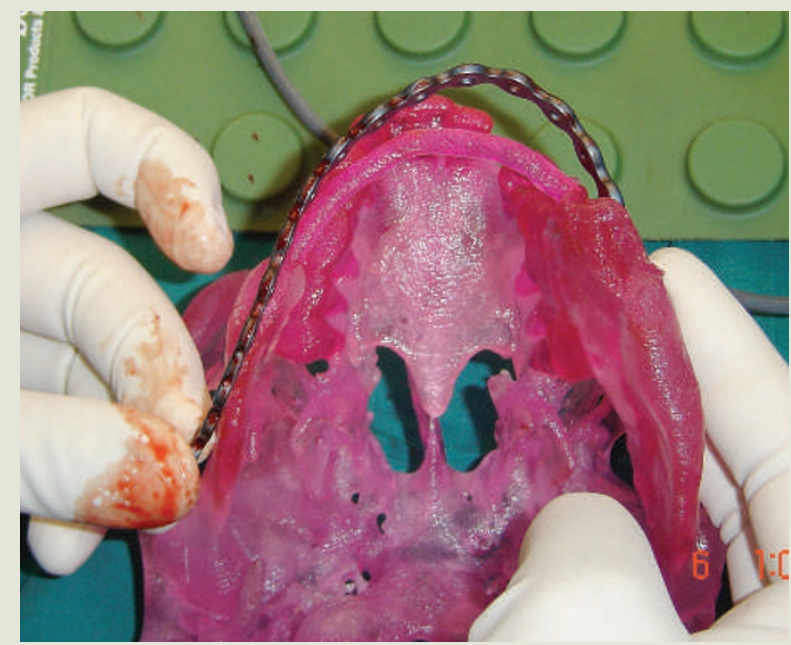

This model was used to aid surgery on an Iraqi civilian.

changes and depression. And he is convinced that the effort on the military side will transfer to civilian practice, noting that thousands of 15-20-year-olds die every year through trauma.

A surprising number of Iraqi civilians have benefited from rapid prototyping technology, thanks to a group calling itself Rapid Prototyping For Baghdad in partnership with Médecins Sans Frontières and an Iraqi dentist. Some 70-90 patients have been treated in Iraq and because of worsening security another 20-30 have been flown to Amman, Jordan, for surgery.

Despite these successes, patients are not always willing to come forward. "Patients are afraid to go to the hospitals," says Omar Al Ani, the dentist. "Before, there was crowding and a very big waiting list for the operations. The bombing and blast injuries have increased, but they are not coming because they are afraid."

E.M. for unknown reasons, and a depressingly high number have been murdered or kidnapped.

\section{All wounds leave scars}

Bassim Irheim Mohammed Al Sheibani of the Diwaniyah College of Medicine in Iraq wrote a letter to the British Medical Journal last October, explaining that there are no drugs, no trained people and no equipment ${ }^{3}$. No aid or assistance has been forthcoming from abroad, apart from some donations from the occupying force, which Sheibani says are often inappropriate. As for personal security, there isn't any. Sheibani himself has received phone threats. His college is planning to provide training courses in emergency medicine for students and doctors, but they lack funds and support.

As for the US military, people are coming home who would have died in previous wars, but some of them are in pretty bad shape (see 'After the battle'). For one doctor, at least, this can seem a mixed blessing. "People do fixate on the body count," says Jadick, "and there are a lot of people who are coming back alive and - I don't know, they maybe shouldn't be. You've always got to think — did we do them any favours? There are some of them that I'm not sure."

Emma Marris is a reporter for Nature based in Washington DC.

1. Holcomb, J., Stansbury, L. G., Champion, H. R., Wade, C. \& Belamy, R. F. J. Trauma 60, 397-401 (2006).

2. Pruitt, B. A. Jr Ann. Surg. 243, 715-729 (2006)

3. Al Sheibani, B. I. M., Hadi, N. R. \& Hasoon, T. Br. Med. J. 333, 847 (2006). 